\title{
Acute Effects of Blood Transfusion on Insulin Sensitivity and Pancreatic $\beta$-Cell Function in Children with $\beta$-Thalassemia/ Hemoglobin E Disease
}

\author{
(D) Somboon Wankanit ${ }^{1}$, (D) Ampaiwan Chuansumrit ${ }^{2}$, (D) Preamrudee Poomthavorn ${ }^{1}$, (D) Patcharin Khlairit $^{1}$, (D) Sarunyu Pongratanakul ${ }^{1}$, \\ (D) Pat Mahachoklertwattana ${ }^{1}$
}

${ }^{1}$ Mahidol University Faculty of Medicine, Ramathibodi Hospital, Department of Pediatrics, Divisions of Endocrinology and Metabolism, Bangkok, Thailand

${ }^{2}$ Mahidol University Faculty of Medicine, Ramathibodi Hospital, Department of Pediatrics, Divisions of Hemato-Oncology, Bangkok, Thailand

\begin{abstract}
What is already known on this topic?
Chronic iron overload in transfusion-dependent thalassemia patients is a cause of insulin resistance and pancreatic $\beta$-cell dysfunction. In addition, severe anemia is also associated with insulin resistance. Essential regular blood transfusions will improve the anemic state in severe thalassemia but will also increase iron accumulation.
\end{abstract}

\section{What this study adds?}

This is the first study that reports the acute effects of blood transfusion on insulin sensitivity and $\beta$-cell function. We demonstrated that following blood transfusion in thalassemic patients, acute iron loading accompanied by partial correction of anemia, resulted in a rise in insulin secretion and a trend towards increasing insulin resistance.

\begin{abstract}
Objective: To assess the acute effects of blood transfusion on insulin sensitivity and pancreatic $\beta$-cell function in thalassemia patients. Methods: Fifty children and adolescents with $\beta$-thalassemia/HbE disease were enrolled in a prospective cohort study. Hemoglobin, serum ferritin and oral glucose tolerance test (OGTT) were performed prior to, and one week after blood transfusion. Insulin sensitivity indices [homeostatic model assessment (HOMA) of insulin resistance (HOMA-IR), whole body insulin sensitivity index (WBISI)] and $\beta$-cell function indices [HOMA of $\beta$-cell function (HOMA- $\beta$ ), insulinogenic index (IGI), and disposition index (DI)] were calculated from glucose and insulin levels obtained during the OGTT.

Results: Following blood transfusion, hemoglobin and serum ferritin increased significantly; 8.5 to $10.1 \mathrm{~g} / \mathrm{dL}$ ( $\mathrm{p}<0.001$ ) and 1764 to $2160 \mathrm{ng} / \mathrm{mL}(\mathrm{p}<0.001)$, respectively. $\beta$-Cell function indices also increased significantly [median HOMA- $\beta$ : 74.3 vs. 82.7 ( $p=0.033$ ); median IGI: 59.6 vs. 79.3 ( $p=0.003$ ); median DI: 658 vs. $794(p=0.01)$ ]. However, the insulin sensitivity index (WBISI) tended to decrease and the insulin resistance index (HOMA-IR) tended to increase although this did not reach significance. Multivariate analysis showed that pre-transfusion serum ferritin was the major factor negatively associated with WBISI and positively associated with HOMAIR, but pre-transfusion hemoglobin had no significant association with insulin sensitivity indices post-transfusion.

Conclusion: This study demonstrated that acute increases in serum ferritin and hemoglobin following blood transfusion in patients with thalassemia might contribute to an increase in insulin secretion and to a trend towards increased insulin resistance.
\end{abstract}

Keywords: Insulin resistance, hemoglobinopathy, iron, hemochromatosis, ferritin 


\section{Introduction}

Thalassemia is a hereditary hemolytic disease caused by hemoglobinopathy. Among patients with moderate to severe disease, regular blood transfusion is a vital modality of treatment. However, chronic blood transfusions result in an increase in total body iron, thus iron overload, which in turn leads to iron deposition in multiple organs, including the pancreas. In animal studies, intravenous iron loading was shown to lead to pancreatic necrosis by free radical oxygen species through a Fenton reaction $(1,2)$. Glucose dysregulation, secondary to increased insulin resistance and pancreatic $\beta$-cell dysfunction, has been widely reported in thalassemia major patients with iron overload $(3,4)$. Furthermore, adverse effects of iron overload on insulin sensitivity and insulin secretion varied, depending on the degree of iron excess and may be reversible after reduction of tissue iron accumulation. In patients with hereditary hemochromatosis, there was a high prevalence of diabetes mellitus and impaired glucose tolerance (IGT) (5). Besides, normalization of serum ferritin by phlebotomy improved insulin secretory capacity (6). In addition, we recently demonstrated that there was a trend towards improvement of insulin sensitivity and $\beta$-cell function following six months of iron chelation therapy in adolescents with nontransfusion-dependent thalassemia (7). Phlebotomy in diabetic patients and blood donation in normal individuals were also shown to improve insulin sensitivity, and thus decrease insulin secretion $(8,9)$.

In addition to increasing the serum iron level, blood transfusions immediately improve the anemic state. Anemia has been shown to be associated with increased insulin resistance in chronic renal failure. Previous studies of chronic renal failure patients treated with multiple episodes of hemodialysis reported that low hematocrit (Hct) may induce tissue hypoxia and cause insulin resistance. Erythropoietin treatment improves the anemic state and reduces insulin resistance in these patients $(10,11,12)$.

Blood transfusion has also been shown to acutely raise serum ferritin level while simultaneously improving the anemic state. These effects can be detected within a week following blood transfusion $(13,14)$. However, the acute effects of blood transfusion on insulin sensitivity and $\beta$-cell function in patients with thalassemia remain unknown. We therefore hypothesized that iron loading, along with improvement of the anemic state following blood transfusion might have negative effects on insulin sensitivity and might adversely increase $\beta$-cell function.

\section{Methods}

This prospective cohort study was conducted at the Department of Pediatrics, Faculty of Medicine, Ramathibodi
Hospital, Bangkok, Thailand during the period from April 2015 to March 2016. Children and adolescents aged 5-20 years and diagnosed with $\beta$-thalassemia/hemoglobin (Hb) E disease, were enrolled into the study. All patients required regular, packed red cell transfusions every four weeks. Patients with other systemic illness, such as diabetes mellitus, chronic renal disease, cardiomyopathy and those taking medications affecting insulin sensitivity and $\beta$-cell function or who had had bone marrow transplantation performed were excluded. Anthropometric data including weight, height, body mass index (BMI) and Tanner's pubertal stage were recorded. Standard deviation (SD) scores of weight and height were calculated using the National Standard Growth Curve of the Ministry of Public Health, Thailand (15). Duration of the disease and median serum ferritin level during the past 3 years were recorded.

After an overnight fast, an oral glucose tolerance test (OGTT) was performed and blood samples were taken for measurement of basal $\mathrm{Hb}$, Hct and serum ferritin. The patients then proceeded to receive packed red cell transfusions at a standardized dose of $10 \mathrm{~mL} / \mathrm{kg}$. One week following the transfusion, all patients underwent a second OGTT as well as measurement of Hb, Hct and serum ferritin.

$\mathrm{Hb}$ was measured using an Abbott Cell Dyne Ruby hematology analyzer (Abbott Diagnostics, Lake Forest, Illinois, USA) within four hours after blood collection. Vitros ferritin assay (Ortho Clinical Diagnostics, Johnson \& Johnson, UK) was used for serum ferritin measurement. For glucose and insulin level assessments, Abbott ARCHITECT c16000 Clinical Chemistry Analyzer (Abbott Diagnostics, Lake Forest, Illinois, USA) and IMMULITE chemiluminescent immunoassay (Siemens Medical Solutions Inc., Malvern, Pennsylvania, USA) were used, respectively.

OGTT was performed in the morning, following an eighthour overnight fast, using $1.75 \mathrm{~g}$ glucose/kg body weight (maximum $75 \mathrm{~g}$ ). Plasma glucose and serum insulin concentrations were determined before and at 30, 60, 90 and 120 minutes following the ingestion of the glucose solution. Each sample was immediately sent to the laboratory right after blood drawing for analytic procedure. The result of the OGTT was interpreted according to American Diabetes Association criteria (16).

Homeostatic model assessment (HOMA) of insulin resistance (HOMA-IR) (17), and whole body insulin sensitivity index (WBISI) (18) were calculated to determine insulin sensitivity. For $\beta$-cell function, HOMA of $\beta$-cell function (HOMA- $\beta$ ) (19), insulinogenic index (IGI) (20) and disposition index (DI) (21) were calculated for assessment of $\beta$-cell function. areas under the curve (AUC) of glucose and insulin were calculated 
using the trapezoidal method. The above-mentioned indices were calculated using the previously published formulas as shown below.

$\begin{aligned} \text { HOMA-IR }= & \frac{\text { Glucose } 0 \mathrm{~min}(\mathrm{mmol} / \mathrm{L}) \times \text { Insulin } 0 \mathrm{~min}(\mu \mathrm{IU} / \mathrm{mL})}{22.5} \\ \text { WBISI }= & \sqrt{\text { [Glucose } 0 \mathrm{~min}(\mathrm{mg} / \mathrm{dL}) \times \text { Insulin } 0 \mathrm{~min}(\mu \mathrm{IU} / \mathrm{mL}) \times} \\ & \text { Mean glucose }(\mathrm{mg} / \mathrm{dL}) \times \text { Mean insulin }(\mu \mathrm{IU} / \mathrm{mL})]\end{aligned}$

HOMA- $\beta=\frac{20 \times \text { Insulin } 0 \mathrm{~min}(\mu \mathrm{IU} / \mathrm{mL})}{\text { Glucose } 0 \mathrm{~min}(\mathrm{mmol} / \mathrm{L})-3.5}$

$\mathrm{IGI}=$

Insulin $30 \mathrm{~min}-$ Insulin $0 \mathrm{~min}(\mathrm{pmol} / \mathrm{L})$

Glucose 30 min-Glucose $0 \mathrm{~min}(\mathrm{mmol} / \mathrm{L})$

$\mathrm{DI}=\mathrm{WBISI} \times \mathrm{IGI}$

This study was approved by the Faculty of Medicine Ramathibodi Hospital, Mahidol University (approval number: 04-58-07; date: 22.04.2015). A written informed consent was obtained from all patients and their legal guardians before the enrollment.

\section{Statistical Analysis}

The data were analyzed using IBM SPSS Statistics version 24.0 (SPSS Inc., Illinois, USA). Data are presented as mean \pm SD for parametric data and median (interquartile range, IQR) for non-parametric data. Paired-samples t-test and Wilcoxon signed-rank test were performed to compare differences between pre- and post-transfusion parameters for parametric and non-parametric parameters, respectively. A chi-square test was used to compare OGTT results between pre-transfusion and post-transfusion samples. Spearman rank test was used for analysis of correlation among parameters. Linear log regression was used for multivariate analysis. A p value of less than 0.05 was considered statistically significant.

\section{Results}

Fifty children and adolescents with $\beta$-thalassemia/HbE disease were enrolled in this study. Clinical characteristics of the patients are shown in Table $1.64 \%$ (32/50) were pubertal and $76 \%$ (38/50) had been receiving only one kind of iron chelator, deferiprone. Short stature and underweight were common. None of them was obese (median Z-score of BMI -0.40 , IQR -1.35 to 0.09 ). Only eight patients (16\%) had a previous history of splenectomy. Serum ferritin levels during the three years prior to enrollment were high (median 1725 , range $362-5740 \mathrm{ng} / \mathrm{mL}$ ). Acute illness was not observed in our patients during the one-week post-transfusion period.

Results of OGTT between pre- and post-transfusion were compared (Table 2). Forty-three (86\%) had normal glucose tolerance (NGT) at both pre- and post-transfusion assessments. Two patients had IGT at both tests. Two patients with NGT before transfusion developed IGT at post-transfusion. One patient with NGT at pre-transfusion had impaired fasting glucose (IFG) at post-transfusion. Conversely, one patient with IGT and another with IFG at pre-transfusion had normal OGTT result at post-transfusion. There was no significant difference between pre- and posttransfusion groups.

Following blood transfusion, there were significant increases in mean $\mathrm{Hb}$ ( 8.5 to $10.1 \mathrm{~g} / \mathrm{dL}$ ), mean Hct (26.6 to $31.4 \%$ ) and median serum ferritin level (1764 to $2160 \mathrm{ng} / \mathrm{mL}$ )

\begin{tabular}{|c|c|}
\hline \multicolumn{2}{|l|}{ Characteristics } \\
\hline Age (years)* & $14(10-16)$ \\
\hline Sex (male/female) (n) & $27 / 23$ \\
\hline \multicolumn{2}{|l|}{ Pubertal stage (n) } \\
\hline - Pre-pubertal & 18 \\
\hline - Pubertal & 32 \\
\hline Z-score of weight* & $-0.57(-1.40$ to 0.58$)$ \\
\hline Z-score of height* & $-0.75(-1.75$ to 0.11$)$ \\
\hline Z-score of BMI* & $-0.40(-1.35$ to 0.09$)$ \\
\hline \multicolumn{2}{|l|}{ Iron chelator used (n) } \\
\hline - None & 1 \\
\hline - Single & 38 \\
\hline - Combined & 11 \\
\hline Splenectomy (n) & 8 \\
\hline Past 3-year ferritin level (ng/mL)* & $1725(362-5740)$ \\
\hline Duration of transfusions (years) ${ }^{*}$ & $9(1-18)$ \\
\hline \multicolumn{2}{|c|}{ *Data are presented as median (interquartile range) } \\
\hline BMI: body mass index & \\
\hline
\end{tabular}

Table 2. Pre-transfusion and post-transfusion oral glucose tolerance test results of all enrolled patients $(n=50)$

\begin{tabular}{llll}
\hline & \multicolumn{2}{l}{ Number of patients } \\
\cline { 2 - 4 } & NGT & IFG & IGT \\
Pre-transfusion & 46 & 1 & 3 \\
Post-transfusion & 45 & 1 & 4 \\
\hline$\chi^{2}=0.154, p=0.93$ & & & \\
NGT: normal glucose tolerance, IFG: impaired fasting glucose, IGT: impaired \\
glucose tolerance
\end{tabular}


(Table 3). Insulin sensitivity tended to decrease following the transfusion as defined by a reduction in WBISI and an increase in HOMA-IR, but these were not statistically significant. However, $\beta$-cell function indices, including HOMA- $\beta$, IGI and DI were all significantly increased following transfusion. Additionally, AUC of plasma glucose obtained during the OGTT pre- and post-transfusion was not significantly different. However, AUC of serum insulin at pre-transfusion was significantly lower than that of the post-transfusion point.

Correlation analysis of pre-transfused $\mathrm{Hb}$ and serum ferritin with insulin sensitivity and $\beta$-cell function indices showed that only pre-transfused ferritin had a negative correlation with percentage change of WBISI $(r=-0.32, p=0.031)$, (data not shown).

Differences in total body iron and anemic state potentially influence the changes in insulin sensitivity and $\beta$-cell function. We therefore performed subgroup analysis according to pretransfused $\mathrm{Hb}$ and pre-transfused serum ferritin (Table 4). Since most of our patients were sub-optimally transfused [mean (SD) pre-transfused $\mathrm{Hb} 8.5(1.1) \mathrm{g} / \mathrm{dL}$ ] and suboptimally iron-chelated [median (IQR) pre-transfused serum ferritin 1764 (799-2662) ng/mL], Hb of $8.5 \mathrm{~g} / \mathrm{dL}$ and serum ferritin of $1500 \mathrm{ng} / \mathrm{mL}$ were used as the cut off points for subgroup analysis. In the low pre-transfused $\mathrm{Hb}$ group $(<8.5$ $\mathrm{g} / \mathrm{dL}$ ), there were significant increases in all $\beta$-cell function indices (HOMA- $\beta$, IGI, DI), but no significant changes in insulin sensitivity indices (HOMA-IR, WBISI) following the transfusion. In comparison, no significant changes in either $\beta$-cell function or insulin sensitivity indices were observed in the high pre-transfused $\mathrm{Hb}$ group $(\geq 8.5 \mathrm{~g} / \mathrm{dL})$. In the high pre-transfused serum ferritin group ( $>1500 \mathrm{ng} / \mathrm{mL}$ ), there was a significant decrease in insulin sensitivity (decreasing
WBISI and increasing HOMA-IR) and significant increases in $\beta$-cell function indices (HOMA- $\beta$, IGI) following transfusion. In contrast, in the low pre-transfused serum ferritin group, there were no changes of insulin sensitivity indices (WBISI, HOMA-IR) and $\beta$-cell function indices (HOMA- $\beta$, IGI), but slightly and significantly increased DI following the transfusion. Using multivariate analysis, pre-transfused serum ferritin was the only factor associated with changes of HOMA-IR $(\mathrm{F}=4.080, \mathrm{p}=0.049)$ and WBISI $(\mathrm{F}=6.799$, $\mathrm{p}=0.012)$.

\section{Discussion}

Studies in patients with thalassemia and hereditary hemochromatosis who had chronic iron overload showed that glucose dysregulation occurred as a result of insulin resistance followed by $\beta$-cell dysfunction $(5,22,23,24)$. Excessive iron causes insulin resistance and subsequently, pancreatic $\beta$-cell apoptosis and insulin deficiency $(25,26)$. Most of our patients had NGT at both pre-transfusion and post-transfusion assessments. Their AUC of plasma glucose remained unchanged following the transfusion, while AUC of serum insulin was increased significantly at posttransfusion, reflecting a rise in $\beta$-cell function. In fact, in the early phase of glucose dysregulation, change of insulin secretion is reciprocal to that of insulin sensitivity. In parallel with AUC of serum insulin, all $\beta$-cell function indices were also elevated following blood transfusion. Meanwhile, there was a trend towards decreasing insulin sensitivity. Therefore, we speculate that acute iron loading, concomitant with partial correction of anemia following a single dose of packed erythrocytes, resulted in a trend towards reduction in insulin sensitivity and thus caused a rise in insulin secretion.

\begin{tabular}{|c|c|c|c|}
\hline Parameters & Pre-transfusion & Post-transfusion & $\mathrm{p}$ \\
\hline Hemoglobin (g/dL) & $8.5 \pm 1.1$ & $10.1 \pm 1.2$ & $<0.001$ \\
\hline Hematocrit (\%) & $26.6 \pm 3.6$ & $31.4 \pm 3.5$ & $<0.001$ \\
\hline Ferritin (ng/mL) & $1764(799-2662)$ & $2160(1095-3033)$ & $<0.001$ \\
\hline WBISI & $11.8(7.6-17.8)$ & $10.1(7.0-17.1)$ & 0.27 \\
\hline НОМА- $\beta$ & $74.3(45.4-109.9)$ & $82.7(56.2-123.4)$ & 0.033 \\
\hline IGI & $59.6(36.2-99.2)$ & $79.3(41.3-135.3)$ & 0.003 \\
\hline DI & $658(374-1135)$ & $794(458-1492)$ & 0.01 \\
\hline
\end{tabular}

HOMA-IR: homeostatic model assessment of insulin resistance, WBISI: whole body insulin sensitivity index, HOMA- $\beta$ : homeostatic model assessment of $\beta$-cell function, IGI: insulinogenic index, DI: disposition index, AUC-G: area under the curve of plasma glucose, AUC-I: area under the curve of serum insulin 


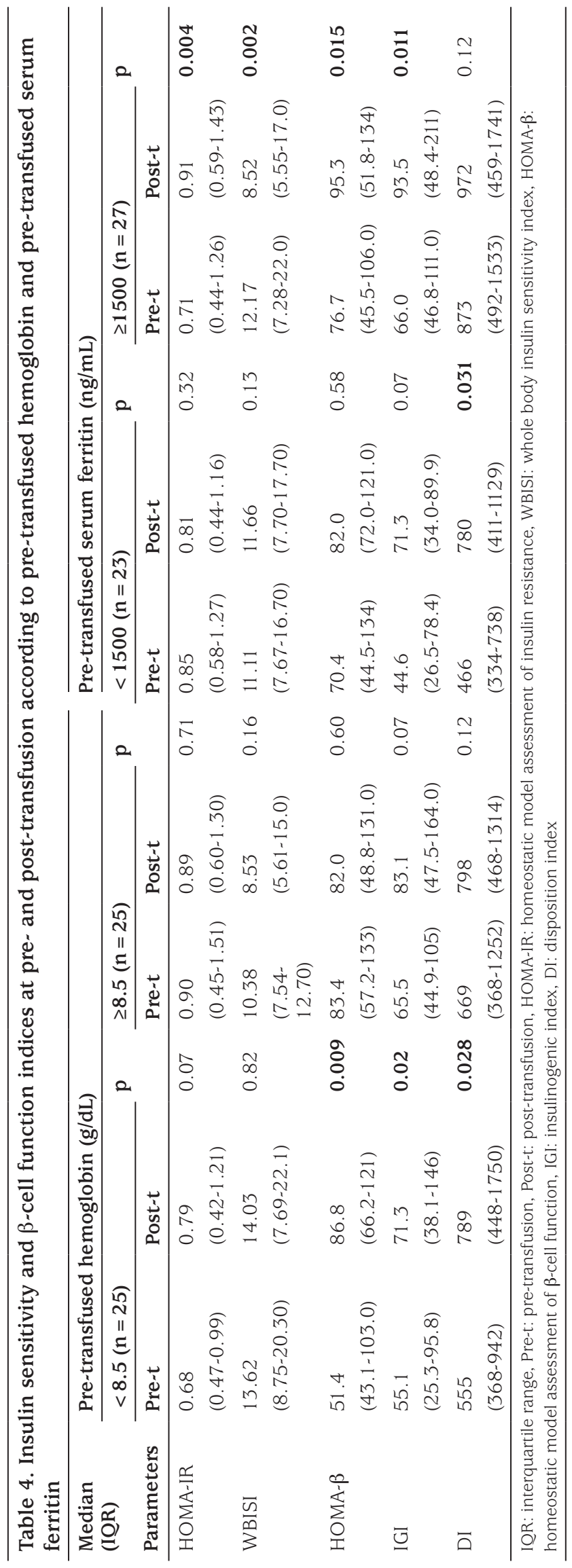

Among patients with chronic renal failure treated with hemodialysis, moderate to severe anemia was also a risk factor for insulin resistance $(10,11,12,27)$. Partial correction of anemia with erythropoietin was shown to reduce insulin resistance as well as reduce insulin secretion $(11,12)$. In chronic renal failure, erythropoietin treatment improved the anemic state with no change of iron status $(11,12)$. In contrast, blood transfusions in thalassemic patients improve the anemic state, but lead to increased iron load.

Considering the present study, acute iron loading from blood transfusion with an increase in serum ferritin about $400 \mathrm{ng} / \mathrm{mL}$ concomitant with an increase in $\mathrm{Hb}$ of about $1.5 \mathrm{~g} / \mathrm{dL}$ caused increased insulin secretion and may have had a detrimental effect on insulin sensitivity. In addition, the acute change in total body iron within only a week may cause increased insulin resistance in chronically transfused patients, particularly in those with relatively high pretransfused serum ferritin. As shown in the multivariate analysis, pre-transfused serum ferritin was the only factor associated with insulin sensitivity indices.

To the best of our knowledge, acute effects of blood transfusion on insulin sensitivity and $\beta$-cell function have not been reported in thalassemia patients. Early changes in insulin sensitivity and $\beta$-cell function may help in understanding the sequences of pathophysiology underlying glucose dysregulation in thalassemia patients.

\section{Study Limitations}

There were some limitations in this study. Firstly, the majority of the patients were sub-optimally transfused and sub-optimally iron-chelated. A high iron store may mask the actual effect of correction of anemia on insulin sensitivity and $\beta$-cell function. Secondly, since $\beta$-thalassemia/HbE disease has a spectrum of severity, that is varied degrees of hemolysis and transfusion requirement, these may be important factors determining insulin sensitivity and $\beta$-cell function. Thirdly, a larger sample size is required for the subgroup analysis to distinguish the effects of anemia from iron overload on insulin sensitivity and $\beta$-cell function. Understanding the relationship between $\mathrm{Hb}$ and glucose homeostasis, independently of iron status would be beneficial in identifying optimal target $\mathrm{Hb}$ for maintaining near-normal insulin sensitivity and $\beta$-cell function.

\section{Conclusion}

Our study has demonstrated that acute increases in serum ferritin and $\mathrm{Hb}$ following blood transfusion in patients with $\beta$-thalassemia may contribute to an increase in insulin secretion and thus to a trend towards increased insulin resistance. 


\section{Acknowledgments}

We appreciate the assistance of Assistant Professor Chusak Okascharoen for statistical advice as well as children and their parents who participated in this study.

\section{Ethics}

Ethics Committee Approval: This study was approved by the Faculty of Medicine Ramathibodi Hospital, Mahidol University (approval number: 04-58-07; date: 22.04.2015).

Informed consent: A written informed consent was obtained from all patients and their legal guardians before the enrollment.

Peer-review: Internally peer-reviewed by all authors.

\section{Authorship Contributions}

Concept: Somboon Wankanit, Ampaiwan Chuansumrit, Preamrudee Poomthavorn, Pat Mahachoklertwattana, Design: Somboon Wankanit, Ampaiwan Chuansumrit, Preamrudee Poomthavorn, Pat Mahachoklertwattana, Data Collection and Processing: Somboon Wankanit, Ampaiwan Chuansumrit, Preamrudee Poomthavorn, Pat Mahachoklertwattana, Patcharin Khlairit, Sarunyu Pongratanakul, Analysis and Interpretation: Somboon Wankanit, Ampaiwan Chuansumrit, Preamrudee Poomthavorn, Pat Mahachoklertwattana, Literature Search: Somboon Wankanit, Ampaiwan Chuansumrit, Preamrudee Poomthavorn, Pat Mahachoklertwattana, Writing: Somboon Wankanit, Ampaiwan Chuansumrit, Preamrudee Poomthavorn, Pat Mahachoklertwattana.

Financial Disclosure: This study was supported by a research grant from the Faculty of Medicine Ramathibodi Hospital, Mahidol University, Bangkok, Thailand.

\section{References}

1. Simcox JA, McClain DA. Iron and diabetes risk. Cell Metab 2013;17:329341

2. Masuda Y, Ichii H, Vaziri ND. At pharmacologically relevant concentrations intravenous iron preparations cause pancreatic beta cell death. Am J Transl Res 2013;6:64-70.

3. Noetzli LJ, Mittelman SD, Watanabe RM, Coates TD, Wood JC. Pancreatic iron and glucose dysregulation in thalassemia major. Am J Hematol 2012;87:155-160.

4. Ghergherehchi R, Habibzadeh A. Insulin resistance and beta cell function in patients with beta-thalassemia major. Hemoglobin 2015;39:69-73.

5. McClain DA, Abraham D, Rogers J, Brady R, Gault P, Ajioka R, Kushner JP. High prevalence of abnormal glucose homeostasis secondary to decreased insulin secretion in individuals with hereditary haemochromatosis. Diabetologia 2006;49:1661-1669.

6. Abraham D, Rogers J, Gault P, Kushner JP, McClain DA. Increased insulin secretory capacity but decreased insulin sensitivity after correction of iron overload by phlebotomy in hereditary haemochromatosis. Diabetologia 2006;49:2546-2551.

7. Chuansumrit A, Pengpis $P$, Mahachoklertwattana P, Sirachainan N, Poomthavorn P, Sungkarat W, Kadegasem P, Khlairit P, Wongwerawattanakoon P. Effect of iron chelation therapy on glucose metabolism in non-transfusion-dependent thalassaemia. Acta Haematol 2017;137:20-26

8. Fernández-Real JM, Peñarroja G, Castro A, García-Bragado F, HernándezAguado I, Ricart W. Blood letting in high-ferritin type 2 diabetes: effects on insulin sensitivity and beta-cell function. Diabetes 2002;51:10001004 .

9. Fernandez-Real JM, Lopez-Bermejo A, Ricart W. Iron stores, blood donation, and insulin sensitivity and secretion. Clin Chem 2005;51:1201-1205.

10. Igaki N, Takashima M, Ohyama M, Oh S, Kida A, Yanase K, Sakai M, Tamada F, Goto T. The beneficial effect of effective control of anemia on hyperinsulinemia and hypoxemia in a hemodialysis patient with corrected transposition of the great arteries. Clin Exp Nephrol 2004:8:163-167.

11. Tuzcu A, Bahceci M, Yilmaz E, Bahceci S, Tuzcu S. The comparison of insulin sensitivity in non-diabetic hemodialysis patients treated with and without recombinant human erythropoietin. Horm Metab Res 2004:36:716-720

12. Rasic-Milutinovic Z, Perunicic-Pekovic G, Cavala A, Gluvic Z, Bokan L, Stankovic S. The effect of recombinant human erythropoietin treatment on insulin resistance and inflammatory markers in non-diabetic patients on maintenance hemodialysis. Hippokratia 2008;12:157-161.

13. Pasricha SR, Frazer DM, Bowden DK, Anderson GJ. Transfusion suppresses erythropoiesis and increases hepcidin in adult patients with beta-thalassemia major: a longitudinal study. Blood 2013;122:124-133.

14. Mahachoklertwattana P, Yimsumruay T, Poomthavorn P, Chuansumrit A, Khlairit P. Acute effects of blood transfusion on growth hormone and insulin-like growth factor-1 levels in children with thalassemia. Horm Res Paediatr 2011;75:240-245.

15. Department of Health, Ministry of Public Health, Thailand: Reference for weight, height and nutritional indices in Thais aged 1 day to 19 years. Bangkok, Department of Health, Ministry of Public Health, Thailand, 2000 .

16. American Diabetes Association. Classification and Diagnosis of Diabetes. Diabetes Care 2016;39(Suppl 1):13-22.

17. Matthews DR, Hosker JP, Rudenski AS, Naylor BA, Treacher DF, Turner RC. Homeostasis model assessment: insulin resistance and beta-cell function from fasting plasma glucose and insulin concentrations in man. Diabetologia 1985;28:412-419.

18. Matsuda M, DeFronzo RA. Insulin sensitivity indices obtained from oral glucose tolerance testing: comparison with the euglycemic insulin clamp. Diabetes Care 1999;22:1462-1470.

19. Albareda M, Rodriguez-Espinosa J, Murugo M, de Leiva A, Corcoy R. Assessment of insulin sensitivity and beta-cell function from measurements in the fasting state and during an oral glucose tolerance test. Diabetologia 2000;43:1507-1511

20. Seltzer HS, Allen EW, Herron AL, Brennan MT. Insulin secretion in response to glycemic stimulus: relation of delayed initial release to carbohydrate intolerance in mild diabetes mellitus. J Clin Invest 1967:323-335

21. Weiss R, Cali AM, Dziura J, Burgert TS, Tamborlane WV, Caprio S Degree of obesity and glucose allostasis are major effectors of glucose tolerance dynamics in obese youth. Diabetes Care 2007;30:18451850 
22. Bhat KG, Periasamy PK. Effect of long-term transfusion therapy on the glycometabolic status and pancreatic Beta cell function in patients with Beta thalassemia major. J Family Med Prim Care 2014;3:119-123.

23. Tangvarasittichai S, Pimanprom A, Choowet A, Tangvarasittichai O. Association of iron overload and oxidative stress with insulin resistance in transfusion-dependent beta-thalassemia major and betathalassemia/HbE patients. Clin Lab 2013;59:861-868.

24. Haap M, Machann J, von Friedeburg C, Schick F, Stefan N, Schwenzer NF, Fritsche A, Häring HU, Thamer C. Insulin sensitivity and liver fat: role of iron load. J Clin Endocrinol Metab 2011;96:E958-961.
25. Cooksey RC, Jouihan HA, Ajioka RS, Hazel MW, Jones DL, Kushner JP, McClain DA. Oxidative stress, beta-cell apoptosis, and decreased insulin secretory capacity in mouse models of hemochromatosis. Endocrinology 2004;1 45:5305-5312.

26. Cario H, Holl RW, Debatin KM, Kohne E. Insulin sensitivity and beta-cell secretion in thalassaemia major with secondary haemochromatosis: assessment by oral glucose tolerance test. Eur J Pediatr 2003;162:139-146.

27. Sit D, Kadiroglu AK, Yilmaz ME, Kara IH, Isikoglu B. The prevalence of insulin resistance and its relationship between anemia, secondary hyperparathyroidism, inflammation, and cardiac parameters in chronic hemodialysis patients. Ren Fail 2005;27:403-407. 